\title{
ABO, Rhesus, and Kell Antigens, Alleles, and Haplotypes in West Bengal, India
}

\author{
Debapriya Basu Suvro Sankha Datta Celina Montemayor Prasun Bhattacharya \\ Krishnendu Mukherjee Willy A. Flegel
}

a Department of Immunohematology and Blood Transfusion, Medical College Hospital, Kolkata, India;

${ }^{b}$ Department of Transfusion Medicine, The Mission Hospital, Durgapur, India;

${ }^{\mathrm{c}} \mathrm{NIH}$ Clinical Center, National Institutes of Health, Bethesda MD, USA

\section{Keywords}

ABO blood group - Donors - Erythrocytes .

Immunohematology · Kell determination · Red blood

cell antigens · Rh phenotyping · Serological typing

\section{Summary}

Background: Few studies have documented the blood group antigens in the population of eastern India. Frequencies of some common alleles and haplotypes were unknown. We describe phenotype, allele, and haplotype frequencies in the state of West Bengal, India. Methods: We tested 1,528 blood donors at the Medical College Hospital, Kolkata. The common antigens of the ABO, Rhesus, and Kell blood group systems were determined by standard serologic methods in tubes. Allele and haplotype frequencies were calculated with an iterative method that yielded maximum-likelihood estimates under the assumption of a Hardy-Weinberg equilibrium. Results: The prevalence of $A B O$ antigens were $B(34 \%)$, $\mathrm{O}(32 \%), \mathrm{A}(25 \%)$, and $A B(9 \%)$ with $A B O$ allele frequencies for $O=0.567, A=0.189$, and $B=0.244$. The $D$ antigen $(\mathrm{RH} 1)$ was observed in $96.6 \%$ of the blood donors with $R H$ haplotype frequencies, such as for $\mathrm{CDe}=$ 0.688809 , cde $=0.16983$ and $\mathrm{CdE}=0.000654$. The $\mathrm{K}$ antigen (K1) was observed in 12 donors $(0.79 \%)$ with $K E L$ allele frequencies for $\mathrm{K}=0.004$ and $\mathrm{k}=0.996$. Conclusions: For the Bengali population living in the south of West Bengal, we established the frequencies of the major clinically relevant antigens in the $A B O$, Rhesus, and Kell blood group systems and derived estimates for the underlying $\mathrm{ABO}$ and $\mathrm{KEL}$ alleles and $\mathrm{RH}$ haplotypes. Such blood donor screening will improve the availability of compatible red cell units for transfusion. Our approach using widely available routine methods can readily be applied in other regions, where the sufficient supply of blood typed for the $\mathrm{Rh}$ and $\mathrm{K}$ antigens is lacking.

(c) 2017 S. Karger GmbH, Freiburg

\section{Introduction}

The antigens of the ABO blood group system are most important in transfusion and organ transplantation. The common antigens of the Rhesus and Kell blood group systems are also frequently tested in blood donors and patients because of their clinical relevance. Several studies from the 1960s addressed ABO and $\mathrm{Rh}$ antigens in various West Bengal populations [1], and several current studies [2-6], conducted in other parts of India, documented the antigen prevalence for the 3 blood group systems. The available data using current technology is limited for the Bengali population in eastern India $[7,8]$ although approximately 91 million people live in the state of West Bengal, bordering Bangladesh to the west and north. The Bengali is one of the largest populations inhabiting one of the most densely populated areas worldwide and has a literacy rate of only $77 \%$. No data have recently been published on blood group allele or haplotype frequencies for this large population.

Blood group data in donors and patients is important for effective management of blood bank inventory. Apart from their relevance in blood transfusion practice and pregnancy management, blood group antigens can inexpensively be applied to medico-legal issues, such as disputed parentage. Blood group data are also useful in guiding population genetic studies for rare alleles that are not easily captured by current mass scale molecular methods. Using current serologic technology, we tested for common $\mathrm{ABO}$, Rhesus,

\section{KARGER}

(c) 2017 S. Karger GmbH, Freiburg
Willy A. Flegel MD

NIH Clinical Center, Department of Transfusion Medicine

National Institutes of Health

Building 10, Room 1C733c (MSC-1184), 10 Center Drive, Bethesda, MD 20892-1184, USA

waf@nih.gov 


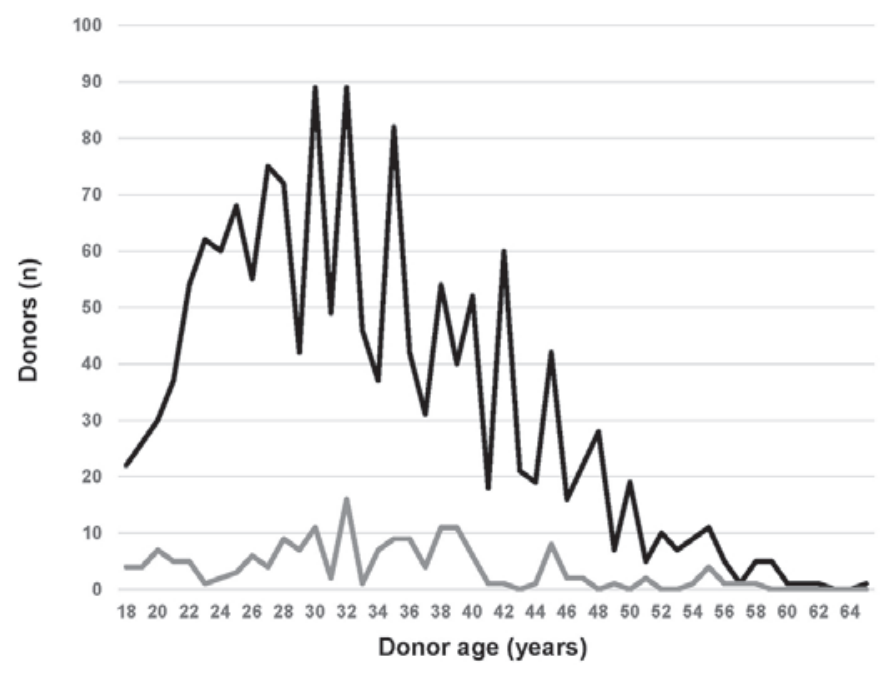

Fig. 1. Blood donor demographics in West Bengal. The 1,528 donors tested in the study (black line) averaged 33.01 years old with a standard deviation of \pm 9.06 years. A quarter of the donors were 26 years or younger (25\% percentile), half of the donors 32 years or younger (mean, $50 \%$ percentile) and three quarters of the donors 39 years or younger (75\% percentile). Female donors (gray line) represented $11 \%$ of all donors.

and Kell blood group antigens and calculated the allele and haplotype frequencies in the Bengali population.

\section{Material and Methods}

\section{Blood Samples}

EDTA-anticoagulated blood samples were collected between January 2014 and June 2015. The blood donors came from Kolkata and adjacent areas in the south of the state of West Bengal. The regular whole blood donations were collected by the Department of Immunohematology and Blood Transfusion of the Medical College Hospital at its main site or nearby outdoor voluntary blood donation drives. Among the approximately 10,000 whole blood donations during the collection period, 1,528 samples from different blood donors were chosen at random. Blood donation camps have been established since, and whole blood donations approximated 30,000 in 2016.

Informed written consent to blood group typing as part of their blood donation was obtained from each donor. Whole blood donations comprised $350 \mathrm{ml}$. Per Government of India regulations, the minimum interval was 3 months. The study was approved by the ethics committee of the West Bengal University of Health Sciences (no. MC/Kol/IEC/128/11-2013).

\section{Immunohematology}

The serologic testing was done as part of the routine standard operating procedure at the Medical College Hospital. Blood group serology was done with conventional tube methods [9-11], mostly using monoclonal antibodies (see Supplementary Material; available at http://content.karger.com/ProdukteDB/ produkte.asp?doi $=475507)[12]$.

\section{Statistical Description}

Phenotype and haplotype frequencies were calculated using the counting method of Ceppellini et al. [13], which yields maximum-likelihood estimates in an iterative process [14], as described previously.[15] An alternative method was also applied for $A B O$ and $K E L$ allele frequency calculation (available at http://content.karger.com/ProdukteDB/produkte.asp?doi=475507) [16]. A twosided chi-square test was performed to compare the frequency distribution of weak D observations between 2 populations [15]. The 95\% confidence interval (CI) was calculated using the Poisson distribution.

\section{Results}

All 1,528 individuals tested in the study were voluntary, unpaid donors for non-directed and non-family whole blood donations. They were between 18 and 65 years old (fig. 1), comprising 1,358 male (89\%) and 1,70 female donors (fig. 1). The data from these donor samples, collected at random and representing approximately $15 \%$ of all, were considered representative of our total donor cohort.

Antigen Frequencies for the Three Major Blood Group Systems

We determined the $\mathrm{ABO}, \mathrm{RHD}$, and Kell antigens (table 1) and calculated maximum-likelihood estimates for the $A B O$ and $K E L$ allele frequencies (table 1) using the counting method [13]; very similar results could be calculated with an alternative, more conventional algorithm [16] (available at http://content.karger.com/ ProdukteDB/produkte.asp?doi $=475507)$.

\section{Antigen and Haplotype Frequencies for the Rhesus Blood Group}

System

We determined the 5 major antigens of the RH blood group system (table 2). Because of the larger number of antigens and concatenated RHCE and RHD alleles ( $R H$ haplotypes), there is no straightforward algorithm to calculate the 8 common $R H$ haplotypes from these phenotype data (table 2). However, the counting method [13] allowed us to determine maximum-likelihood estimates for the $R H$ haplotypes (table 3 ), as described previously (supplemental fig. 1 available at http://content.karger.com/ ProdukteDB/produkte.asp?doi $=475507)$ [15].

\section{Weak $D$ in India}

No sample of serologic weak D phenotype was observed (table 2), and the prevalence of the serologic weak D phenotype was calculated to be $0.215 \%$ or less (upper $95 \%$ limit of the expected frequency) among Bengali blood donors. Compared to a German population (mean of $0.44 \%$ among all donors) [15], the difference is statistically significant ( $\mathrm{p}=0.0192$, chi-square test, two-sided).

\section{Discussion}

The present study was conducted to obtain blood group data for volunteer blood donors in West Bengal, India, using standardized current technology. We determined the phenotype frequencies of the common $\mathrm{ABO}$, Rhesus, and Kell blood group antigens. The prevalence of alleles and haplotypes were calculated using a counting method. The data corroborated the prevalence of the common blood group antigens for the large Bengali population and aided in creating a donor database. Now we can more readily supply antigen-negative blood that is compatible for patients with multiple alloantibodies.

The B antigen was most prevalent in the eastern parts of India (table 1), similar to reports from Northern India $[3,4]$. Large co- 
Table 1. Frequencies of ABO, RHD, and Kell phenotypes

\begin{tabular}{|c|c|c|c|c|c|}
\hline \multirow[t]{2}{*}{ Blood group } & \multicolumn{3}{|l|}{ Serology } & \multicolumn{2}{|c|}{ Molecular genetics } \\
\hline & phenotype & frequency, $\%$ & observations, $\mathrm{n}$ & allele & frequency (fraction) \\
\hline \multirow[t]{4}{*}{$\mathrm{ABO}$} & A & 25.13 & 384 & $\mathrm{~A}$ & 0.189 \\
\hline & B & 33.77 & 516 & B & 0.244 \\
\hline & $\mathrm{O}$ & 32.07 & 490 & $\mathrm{O}$ & 0.567 \\
\hline & $\mathrm{AB}$ & 9.03 & 138 & n.a. & \\
\hline \multirow[t]{4}{*}{ Rhesus } & D positive ${ }^{*}$ & 96.60 & 1476 & n.a. & \\
\hline & D negative & 3.40 & 52 & n.a. & \\
\hline & ccddee & 2.75 & 42 & n.a. & \\
\hline & dd with $\mathrm{C}$ and/or $\mathrm{E}$ & 0.65 & 10 & n.a. & \\
\hline \multirow[t]{3}{*}{ Kell } & KK (K positive) & 0 & 0 & n.a. & \\
\hline & $\mathrm{Kk}(\mathrm{K}$ positive $)$ & 0.79 & 12 & K & 0.0039 \\
\hline & kk (K negative) & 99.21 & 1516 & $\mathrm{k}$ & 0.9961 \\
\hline
\end{tabular}

n.a. = Not applicable.

${ }^{*}$ No weak serologic reactivity was observed for D antigen testing among the 1,528 samples. The upper limit of the $95 \%$ confidence interval for a serologic weak D phenotype is 1 in 465.14 among all blood donors $(0.215 \%)$. horts from other parts of India had a slight preponderance of blood group $\mathrm{O}[2,6]$. The prevalence of the Rhesus antigens was similar to previous reports for Delhi, India [4]. The CCDEE phenotype was rare but more frequently observed $(\mathrm{n}=4$, table 2$)$ than was predicted by our calculations of the $C D E$ haplotype $(\mathrm{n}=0$, table 3$)$; the 4 donors were unrelated based on the donors' residence, name, religion, location, and date of blood donation (data not shown). The prevalence of Kell antigens varied markedly among Indian populations: Thakral et al. [4] reported for Northern India a K prevalence of $5.68 \%$, which almost resembles the European situation, for instance $7.82 \%$ in Germany [11]; in West Bengal the $\mathrm{K}$ prevalence was $0.79 \%$ (table 1 ), more typical for most non-Caucasian populations [5].

The studied population was expected to be homogeneous, because the study area was restricted to Kolkata and adjacent districts in the state's south. Tribal ethnic groups, such as Rajbansi and Lepcha, with possibly different blood group frequencies are living in the state's north and adjoining mountainous areas of the Himalaya.

In our region, $5.6 \%$ of the population carries the $\beta$-thalassemia trait and $5.0 \%$ the hemoglobin E (HbE) trait [17]. Patients can be heterozygous for the $\mathrm{HbE}$ and $\beta$-thalassemia alleles or homozygous for either the $\mathrm{HbE}$ or $\beta$-thalassemia allele [17]. Because the majority of these patients is transfusion-dependent and prone to alloimmunization [18, 19], we detected red cell alloantibodies to blood group antigens in $5.6 \%$ of multiply transfused patients with $\beta$-thalassemia disease at our hospital in Kolkata [20]. Knowledge of the antigen prevalence allows us to predict the number of red cell units that need to be typed when searching for antigen-negative units. If all donors would eventually be typed [21], as is routine and cost effective in many Western health care systems [15], allocating an e-negative unit [11,22], for instance, would be easy, because at any given time more than 10 such ccDEE units are expected to be on the shelf at our hospital.
Table 2. Frequencies of Rhesus phenotypes

\begin{tabular}{|c|c|c|}
\hline Phenotype & Rh phenotypes observed, $\mathrm{n}$ & Frequency, $\%$ \\
\hline CcDee & 424 & 27.75 \\
\hline CCDee & 749 & 49.02 \\
\hline $\mathrm{CcDEe}$ & 210 & 13.74 \\
\hline $\mathrm{ccDEe}$ & 52 & 3.40 \\
\hline ccDEE & 11 & 0.72 \\
\hline ccDee & 15 & 0.98 \\
\hline CCDEe & 11 & 0.72 \\
\hline CcDEE & 0 & 0 \\
\hline CCDEE & 4 & 0.26 \\
\hline Subtotal & 1,476 & 96.60 \\
\hline ccddee & 42 & 2.75 \\
\hline Subtotal & 42 & 2.75 \\
\hline Ccddee & 8 & 0.52 \\
\hline CCddee & 0 & 0 \\
\hline CcddEe & 0 & 0 \\
\hline ccddEe & 2 & 0.13 \\
\hline ccddEE & 0 & 0 \\
\hline CcddEE & 0 & 0 \\
\hline CCddEE & 0 & 0 \\
\hline Subtotal & 10 & 0.65 \\
\hline Total & 1,528 & 100 \\
\hline
\end{tabular}

Antibody screening and identification methods employ commercial red cell panels, often prepared from donors of Western countries who may have a different antigen profile relative to Indian patients. The $\mathrm{Mi}^{\mathrm{a}}$ antigen, frequent in South East Asia but apparently rare in Delhi [23], could be investigated in the Bengali population along with the $\mathrm{U}, \mathrm{Mur}, \mathrm{Di}^{\mathrm{a}}, \mathrm{In}^{\mathrm{a}}$, and variant $\mathrm{Rh}$ antigens. Rare red cells, including these and other clinically relevant indigenous antigen features, could be included in panels for anti- 
Table 3. Frequencies of Rhesus haplotypes

\begin{tabular}{|c|c|c|c|c|c|c|c|c|}
\hline & \multicolumn{8}{|c|}{ Haplotypes } \\
\hline & cde & $\mathrm{CDe}$ & $\mathrm{cDE}$ & $\mathrm{cDe}$ & Cde & $\mathrm{cdE}$ & $\mathrm{CDE}$ & $\mathrm{CdE}$ \\
\hline Frequency & 0.16983 & 0.688809 & 0.088024 & 0.027814 & 0.013743 & 0.003927 & 0.007199 & 0.000654 \\
\hline
\end{tabular}

body detection. Antigen screening of the major blood group systems will also aid in selecting red cells for developing panels locally.

The age distribution of the blood donors (fig. 1) may be representative for a growing population of relatively low average age. These details contrasted to some Western populations and their donor age distributions [24]. The fluctuation in donor numbers per age cohorts (fig. 1) may be random, as most cohorts are small, but could also be explained by donors living in villages with lower than average literacy rates, where a few of them may not even know their exact age. While the exact reasons for the almost yearly alternating donor numbers (fig. 1) remain unknown, they should be explored to better understand the donor demographics and possible data reporting issues. Female donors were underrepresented, which may be typical for donors in India, perhaps based on cultural attitudes. However, the generally low weight and body mass index may more readily produce borderline low hemoglobin concentrations in repeat female donors preventing them from donating blood more frequently.

Our observation of 4 rare CCDEE phenotypes among only 1,528 donors (table 2) emphasizes that a fresh look at routine blood group data can be rewarding [25]. The discrepancy between the observation and CDE allele frequency calculation (table 3) should prompt further study of the donors' phenotypes and haplotypes. Methodically studying blood group data, particularly based on methods newly applied to a donor population, continues to be worthwhile, even when utilizing methods that are standard in other regions of the world. Implementation of such methods in the blood service routine in West Bengal has the potential to aid in clinical care and patient safety $[26,27]$.

\section{Acknowledgment}

We thank Dr. Biplabendu Talukder and Dr. Somnath Mukherjee for their general support during data collection and Dr. Franz F. Wagner for reviewing the manuscript. Part of the work was conducted by Debapriya Basu as thesis project for her MD degree by research at The West Bengal University of Health Sciences, Kolkata, India [16].

This work was supported by the Intramural Research Program (project ID Z99 CL999999) of the NIH Clinical Center.

\section{Authorship Contribution}

DB and SSD designed the study, performed serologic testing, and wrote drafts. CM and WAF developed a spreadsheet for the counting method and calculated the allele and haplotype frequencies. PB and KM discussed data. All authors reviewed and edited the manuscript. WAF analyzed all data and wrote the manuscript.

\section{Statement of Disclaimer}

The opinions expressed in this review are those of the authors and do not necessarily represent the views or policies of the National Institutes of Health, the Department of Health and Human Services, or the U.S. Federal Government.

\section{Disclosure Statement}

The authors declared having no competing financial interest relevant to this article.

\section{References}

1 Mourant AE, Kopec AC, Domaniewska-Sobczak K: The Distribution of the Human Blood Groups and other Polymorphisms, 2 ed. London, Oxford University Press, 1976.

2 Das PK, Nair SC, Harris VK, Rose D, Mammen JJ, Bose YN, Sudarsanam A: Distribution of ABO and Rh-D blood groups among blood donors in a tertiary care centre in South India. Trop Doct 2001;31:47-48.

3 Thakral B, Saluja K, Sharma RR, Marwaha N: Phenotype frequencies of blood group systems (Rh, Kell, Kidd, Duffy, MNS, P, Lewis, and Lutheran) in north Indian blood donors. Transfus Apher Sci 2010;43:17-22.

4 Makroo RN, Bhatia A, Gupta R, Phillip J: Prevalence of Rh, Duffy, Kell, Kidd \& MNSs blood group antigens in the Indian blood donor population. Indian J Med Res 2013;137:521-526.
5 Kahar MA, Patel RD: Phenotype frequencies of blood group systems (Rh, Kell, Kidd, Duffy, MNS, P, Lewis, and Lutheran) in blood donors of south Gujarat, India. Asian J Transfus Sci 2014;8:51-55.

6 Agrawal A, Tiwari AK, Mehta N, Bhattacharya P, Wankhede R, Tulsiani S, Kamath S: ABO and Rh (D) group distribution and gene frequency; the first multicentric study in India. Asian J Transfus Sci 2014;8: 121-125.

7 Datta UK, Mondal S, Mukherjee S: A study of the distribution of $\mathrm{ABO}$ and $\mathrm{Rh}(\mathrm{D})$ blood groups amongst Lodha tribe in Midnapore district of West Bengal. J Indian Med Assoc 1997;95:497-498, 506.

8 Nag I, Das SS: ABO and Rhesus blood groups in potential blood donors at Durgapur Steel city of the district of Burdwan, West Bengal. Asian J Transfus Sci 2012;6: $54-55$.
9 Cooling L: ABO, $\mathrm{H}$ and Lewis blood groups and structurally related antigens; in Fung MK, Grossman BJ, Hillyer CD, Westhoff CM (eds): Technical Manual. Bethesda, AABB, 2014, pp 291-315.

10 Datta SS, Mukherjee S, Bhattacharya P, Mukherjee K: Anti-JK-a antibody in a case of SLE patient with Plasmodium falciparum malaria infection. Indian J Hematol Blood Transfus 2013;29:106-109.

11 Datta SS, Reddy M, Basu S: Warm autoimmune hemolytic anemia with mimicking anti-e specificity causing intravascular hemolysis in a chronic ITP patient. Transfus Apher Sci 2015;53:205-207.

12 Sandler SG, Flegel WA, Westhoff CM, Denomme GA, Delaney M, Keller MA, Johnson ST, Katz L, Queenan JT, Vassallo RR, Simon CD: It's time to phase in RHD genotyping for patients with a serologic weak D phenotype. Transfusion 2015;55:680-689. 
13 Ceppellini R, Siniscalco M, Smith CAB: The estimation of gene frequencies in a random-mating population. Ann Hum Genet 1955;20:97-114.

14 Thomas A, Camp NJ: Maximum likelihood estimates of allele frequencies and error rates from samples of related individuals by gene counting. Bioinformatics 2006;22:771-772.

15 Wagner FF, Kasulke D, Kerowgan M, Flegel WA: Frequencies of the blood groups $\mathrm{ABO}$, Rhesus, D category VI, Kell, and of clinically relevant high-frequency antigens in South-Western Germany. Infusionsther Transfusionsmed 1995;22:285-290.

16 Basu D: Prevalence of ABO, Rh Phenotype, Extended Rh and Kell Antigen in Voluntary Blood Donor Population of South Bengal - a Study from Tertiary Care Hospital in Eastern India. PhD thesis, Department of Immunohaematology \& Blood Transfusion, The West Bengal University of Health Sciences. Kolkata, India, 2016.

17 Mukhopadhyay D, Saha K, Sengupta M, Mitra S, Datta C, Mitra PK: Spectrum of hemoglobinopathies in West Bengal, India: a CE-HPLC study on 10407 subjects. Indian J Hematol Blood Transfus 2015;31:98-103.
18 Jain R, Choudhury N, Chudgar U, Harimoorthy V, Desai P, Perkins J, Johnson ST: Detection and identification of red cell alloantibodies in multiply transfused thalassemia major patients: a prospective study. Indian J Hematol Blood Transfus 2014;30:291-296.

19 Philip J, Biswas AK, Hiregoudar S, Kushwaha N: Red blood cell alloimmunization in multitransfused patients in a tertiary care center in Western India. Lab Med 2014;45:324-330.

20 Datta SS, Mukherjee S, Talukder B, Bhattacharya P, Mukherjee K: Frequency of red cell alloimmunization and autoimmunization in thalassemia patients: a report from Eastern India. Adv Hematol 2015;2015:610931.

21 Kulkarni S, Vasantha K, Ghosh K: Antigen negative red blood cell inventory of Indian blood donors. Transfus Apher Sci 2016;55:131-135.

22 Sachan D, Kumar A, Jothimani D, Rela M: Delayed serological transfusion reaction after platelet transfusion due to anti-e. Indian J Hematol Blood Transfus 2016; 32:287-289.
23 Makroo RN, Bhatia A, Chowdhry M, Rosamma NL, Karna P: Frequency of Mi(a) antigen: a pilot study among blood donors. Indian J Med Res 2016;143:633635 .

24 Greinacher A, Fendrich K, Alpen U, Hoffmann W: Impact of demographic changes on the blood supply: Mecklenburg-West Pomerania as a model region for Europe. Transfusion 2007;47:395-401.

25 Flegel WA: A rewarding fresh look at routine blood group data. Blood Transfus 2008;6:182-183.

26 Pahuja S, Pujani M, Gupta SK, Chandra J, Jain M: Alloimmunization in thalassemics: a comparision between recipients of usual matched and partial better matched blood. An evaluation at a tertiary care centre in India. Blood Transfus 2014;12(suppl 1):s100-s104.

27 Makroo RN, Agrawal S, Bhatia A, Chowdhry M, Thakur UK: Impact of antigenic exposures and role of molecular blood grouping in enhancing transfusion safety in chronically transfused thalassemics. Asian J Transfus Sci 2016;10:140-144. 